\title{
IDENTIFYING LONG RUN SUPPLY CURVE IN INDIA
}

\author{
Ashima Goyal* \\ Ayan Kumar Pujari ${ }^{\dagger}$
}

December 1, 2004

\begin{abstract}
Identifications of a vertical and then a horizontal supply curve are successively imposed on Indian time series inflation and industrial output growth data in a two equation Structural Vector Autoregression (SVAR). The results serve as tests of the identifications. On balance they imply a high elasticity of long-run supply, because supply shocks have a large impact on inflation; demand has a large effect on output growth and a persistent effect on output levels. Estimated structural shocks capture historical recessions and turning points well. Policy demand shocks aggravated negative supply shocks or failed to take full advantage of positive supply side developments.
\end{abstract}

Key words: Horizontal and Vertical Long-Run Supply Curve, Demand and Supply Shocks, Structural VAR, Identification, Historical Decomposition

JEL Classification: C32, E31, E32

\footnotetext{
${ }^{*}$ Corresponding author: Professor, Indira Gandhi Institute of Development Research (IGIDR), Gen. A.K. Vaidya Marg, Goregaon (E) Mumbai 400 065, India. Ph:+91-22-2840 0920, Fax: +9122-2840 2752, E-mail: ashima@igidr.ac.in

${ }^{\dagger}$ Research scholar at IGIDR, Mumbai, E-mail: ayan@igidr.ac.in
} 


\section{Introduction}

If macroeconomic price and output series have a unit root, it implies that shocks have long-run effects on the variables. Considering the simplest aggregate demand, aggregate supply model as generating the price and output series, these shocks can be understood as shifting the two curves, and broadly classified as demand and supply shocks.

Looking at a time series of price and output is it possible to decompose the share of the changes originating from demand and supply shocks? In a dynamic simultaneous equation system, some identifying restrictions in a Structural Vector Autoregression (SVAR) representation are required to identify structural shocks. There is an underlying assumption that the two aggregate shocks represent the average dynamic effects of potentially many underlying shocks. The averaging process is useful in sofar as demand and supply are conceptually distinct categories. Their usefulness is demonstrated in the aggregate demand and supply curves that survive in all macroeconomic textbooks. The large number of lags involved imply that large size VAR models quickly run into the curse of dimensionality. Therefore small models have an advantage especially when we want, as in this paper, to systematically compare the effects of two polar identifications.

In the literature (Blanchard and Quah, 1989, Quah and Vahey, 1995), it is common to impose the identifying restriction that the aggregate supply curve is vertical in the long-run. Then aggregate demand shocks have no long-run effect on output. This is the output neutrality assumption. If the economy is at full employment in the long-run, a rise in demand due to monetary or fiscal policy cannot raise output but contributes only to a price rise. This mainstream macroeconomic convention may be a valid long-run approximation for a mature economy that is near full-employment. But there is an established literature that allows demand to have long-run effects either through multiple equilibria (Farmer, 1999) or through hysterisis effects (Blanchard and Summer, 1987). Mankiw and Romer (1991) have a collection of articles on these issues.

A labor surplus country such as India cannot be regarded as being anywhere near full employment. There tend to be short-term supply bottlenecks which if relieved allow an expansion of employment at a constant real wage, or one that rises with productivity. Therefore, a flat long-term supply curve may be a valid identification 
for such a country until it reaches full maturity and absorption of its labor surplus. Globalization and more foreign inflows have relaxed the foreign exchange constraint which used to be one of the major bottlenecks.

In this paper we test two alternative decompositions of structural shocks for the Indian economy. Allowing for a non-zero equilibrium rate of inflation and a positive output growth, the decomposition gives us the relative size and effect of demand and supply shocks on inflation, output growth and levels. First, the restriction is imposed that demand shocks can have no long-run effect on output. The size of the other shocks and size and speed of all the shocks obtained gives an indirect test of the identification adopted.

It turns out that the relative size of supply shocks is larger than that warranted by such a structure of long-run supply. The size also exceeds that found in similar decompositions estimated in developed countries.

The second identification restriction tested for the dynamic structural VAR is that demand shocks have no long-run effect on inflation. The results serve as a test of the two identifications and support a high long-run supply elasticity in the Indian economy. Comparing the relative size of demand and supply shocks under such an identification, with the earlier one, yields useful insights.

Results on the historical relative contribution of demand and supply shocks to inflation and industrial output growth illustrate the impact of oil shocks and the interaction of macroeconomic policy with structural adjustment that was a part of the ongoing reform process during the nineties. Macroeconomic policy would be part of demand shock while structural reform would add to supply shocks.

The results also contribute to the debate about the conditions under which demand can have long-run effects.

This paper has been organized in the following manner. Section 2 explains the identification problem in an SVAR model. The information about data and methodology have also been presented in this section. Section 3 discusses the obtained results and Section 4 analyzes the demand and supply components of output growth and inflation. The conclusion is in Section 5. 


\section{Identifying the SVAR}

Consider a $V A R(p)$ model, which can be expressed as follows:

$$
\begin{array}{r}
Z_{t}=\alpha+A_{1} Z_{t-1}+A_{2} Z_{t-2}+\cdots+A_{p} Z_{t-p}+e_{t} \\
\Rightarrow\left(1-L-L^{2}-L^{p}\right) Z_{t}=\alpha+e_{t} \\
\Rightarrow A(L) Z_{t}=\alpha+e_{t}, \quad e_{t} \sim \mathrm{N}(0, \Omega)
\end{array}
$$

where $Z_{t}$ is a covariance stationary vector, $A(L)$ is the matrix of lag operator, $\alpha$ is an intercept vector and $e_{t}$ is an error vector. The Wold (moving average) representation of Equation 1 would be

$$
Z_{t}=C(L) e_{t}
$$

where $C(L)=A(L)^{-1}$ and $C_{0}=I$. In this representation, the elements of $e_{t}$ are contemporaneously correlated.

Now suppose that the behavior of $Z_{t}$ is governed by independent structural shocks (innovations), which need to be identified in order to know the movement of the components of $Z_{t}$ with respect to the individual shocks. Suppose that the Wold representation with the structural shocks takes the following form:

$$
Z_{t}=D(L) \epsilon_{t}, \quad \text { where } \epsilon_{t} \sim N(0, I)
$$

As mentioned earlier, the components of $\epsilon_{t}$ are orthogonal to each other, which need to be identified. The SVAR approach intend to identify such structural innovations. There are many ways to handle this problem, out of which we will follow the one, suggested by BQ (Blanchard and Quah, 1989), which makes the use of long run restrictions. Let us discuss how to identify the components of $\epsilon_{t} \cdot{ }^{1}$ From Equation 2 and Equation 3,

$$
\begin{aligned}
e_{t}=D_{0} \epsilon_{t} \text { and } C_{j} D_{0} & =D_{j} \\
\Rightarrow C(L) D_{0} & =D(L) \\
\Rightarrow \Omega & =D_{0} D_{0}^{\prime} \text { Since } \operatorname{Var}(\epsilon)=\mathrm{I}
\end{aligned}
$$

After obtaining the $D_{0}$ matrix it can be used to identify $\epsilon_{t}$ with the help of $e_{t}$.

In a bi-variate model, $D_{0}$ consists of four elements, which necessitates four restrictions

\footnotetext{
${ }^{1}$ Giannini (1992), Enders (2004) and Bjornland (2001).
} 
for identification. The symmetry of the matrix $\Omega=\operatorname{Var}\left(e_{t}\right)$ and the normalization conditions impose three restriction. Therefore, we need only one more restriction to identify $D_{0}$. Following BQ, if we can impose a long run restriction, then the structural innovations can be identified. In a bi-variate set up like ours, the long run expression of Equation 3 can be written as:

$$
\left(\begin{array}{l}
\Delta z_{1 t} \\
\Delta z_{2 t}
\end{array}\right)=\left(\begin{array}{ll}
D_{11}(1) & D_{12}(1) \\
D_{21}(1) & D_{22}(1)
\end{array}\right)\left(\begin{array}{l}
\epsilon^{1} \\
\epsilon^{2}
\end{array}\right)
$$

where $D(1)=\sum_{j=0}^{\infty} D_{j}$ is the long run matrix of $D(L)$. With a long-run restriction $D_{12}(1)=0, D(1)$ will be a lower triangular matrix. from Equation $4, C(1) D_{0}=D(1)$. With Equation 5,

$$
\begin{gathered}
\Rightarrow C(1) D_{0} D_{0}^{\prime} C(1)^{\prime}=D(1) D(1)^{\prime} \\
\Rightarrow C(1) \Omega C(1)^{\prime}=D(1) D(1)^{\prime}
\end{gathered}
$$

Given the estimates of $\Omega$ and $C(1), D(1)$ will be the unique lower triangular Choleski factor of $C(1) \Omega C(1)^{\prime}$, since $D(1)$ is lower triangular. The structural shocks can now be easily computed by using

$$
D_{0}=C(1)^{-1} M
$$

where $M$ is the lower triangular Choleski decomposition of Equation 7. The structural shocks would be obtained with the help of $D_{0}$ and $e_{t}$ using the relation $e_{t}=D_{0} \epsilon_{t}$, where $e_{t}$ is the residual from estimating the reduced form VAR, i.e., Equation 1.

In the present context, $Z$ comprises change in the logarithm of output and inflation, $\Delta y$ and $\Delta p$. Their behavior is governed by two kinds of structural innovations, that is, supply shocks and demand shocks. We estimate two separate SVAR models with these two variables, by altering their order. In both the models, however, the order of the structural shocks remains the same. Supply shocks are $\epsilon^{1}$ demand shocks $\epsilon^{2}$ respectively.

In our analysis the first model is the vertical supply curve (VSC) model, $Z_{t}=$ $\left(\begin{array}{ll}\Delta y & \Delta p\end{array}\right)$. The assumption that demand shocks have no impact on $\Delta y$ in the long run, gives us a vertical long run supply curve. This corresponds to long run neutrality assumption where inflation fails to raise output in the long run. This model is equivalent to long run Phillips curve and Lucas vertical supply curve. The long-run restriction makes $D_{12}(1)=0$, so that $D(1)$ is a lower triangular matrix. 
Once the structural shocks and the sequence of $D^{\prime} s$ are estimated, the long - run effect of supply shocks on output growth is given by $\sum_{j=0}^{\infty} D_{11}(j) \epsilon^{1}(t-j)$, while the long-run effect of demand on output growth is zero. Inflation is decomposed as the sum of supply and demand shocks respectively:

$$
\Delta p=\sum_{j=0}^{\infty} D_{21}(j) \epsilon^{1}(t-j)+\sum_{j=0}^{\infty} D_{22}(j) \epsilon^{1}(t-j)
$$

The second model is called the horizontal supply curve (HSC) model. Here $Z_{t}=$ $\left(\begin{array}{ll}\Delta p & \Delta y\end{array}\right)$. Here, we assume demand shocks to have no impact on inflation in the long run. Therefore, this provides a horizontal long run supply curve. The long-run restriction again makes $D_{12}(1)=0$, so that $D(1)$ is a lower triangular matrix, but because of the change in order of the variables it now implies a horizontal supply curve.

Again, once the structural shocks and the sequence of $D^{\prime} s$ are estimated, the long run effect of supply shocks on inflation is given by $\sum_{j=0}^{\infty} D_{11}(j) \epsilon^{1}(t-j)$, while the long-run effect of demand on inflation is zero. Output growth is decomposed as due to the sum of supply and demand shocks respectively:

$$
\Delta y=\sum_{j=0}^{\infty} D_{21}(j) \epsilon^{1}(t-j)+\sum_{j=0}^{\infty} D_{22}(j) \epsilon^{1}(t-j)
$$

These decompositions are presented and discussed in Section 4. Note that in both the models shock 1 and shock 2 refer to supply shocks and demand shocks respectively.

\section{$2.1 \quad$ Tests of the identifications}

In both the models, we do not restrict the length of horizon for the long run impact to be neutralized. That is, we allow the data to reveal it, which can be observed through the impulse response functions presented later. The impulse response functions, in fact, are indicators of the validity of our assumptions.

The vertical supply curve (VSC) holds only at medium to long-horizons. It does not restrict how quickly demand shocks become output neutral. Therefore the speed of response serves as a test of the identification imposed. 
Such a structure of aggregate demand and supply implies that (i) supply shocks should have little sustained impact on measured inflation, (ii) demand shocks should account for the major part of measured inflation, (iii) supply shocks should have a sustained impact on output levels. Since these restrictions are not imposed as identifying conditions, they serve as tests. If the results differ it would shed doubt on the identification procedure.

Similarly, the horizontal supply curve (HSC) would only hold at medium to longhorizons. A short-term expansion of output may require a rise in inflation, which falls only when short-term bottlenecks are removed. The HSC does not restrict how quickly the effect of demand shocks on inflation falls. Therefore the speed of inflationresponse to demand shocks serves as a test of the identification imposed.

Such a structure of aggregate demand and supply implies that (i) demand shocks should have a sustained impact on output levels (ii) supply shocks should account for the major part of measured inflation (iii) demand shocks should have little sustained impact on inflation. If the results differ it would shed doubt on the horizontal long-run supply curve used as the identification procedure.

Although the assumption is made that the two disturbances are uncorrelated or orthogonal to each other at all leads and lags this allows policy causing one type of shock to react to another. Orthogonality may break down at specific points but there should be no systematic correlation for the procedure to be valid.

\subsection{Data and Methodology}

For the present analysis, we have used data for monthly WPI and IIP (proxy for output) from IFS (International Financial Statistics)-CD-ROM, published by the International Monetary Fund (IMF). Our dataset covers a time period from January 1971 to September 2003, dealing with 392 observations. The base year for all the series is 1995. $p$ and iip are the wholesale price index (WPI) and index of industrial production (IIP) in logarithmic terms. Before our exercise, we found that iip takes a peak almost in each year, around in the month of March. The plot of $\log$ (IIP) has been given in Figure 1. Therefore, we deseasonalise the series using dummy variables for the months. Then we nullify the inflationary effect from it to make it a real variable. This has been done by taking the difference of $\log ($ IIP) to $\log$ (WPI). Then the resultant series has been taken as a proxy for monthly real output $(y)$. 
Figure 1: IIP Series from Jan. 1971 to Sep. 2003.

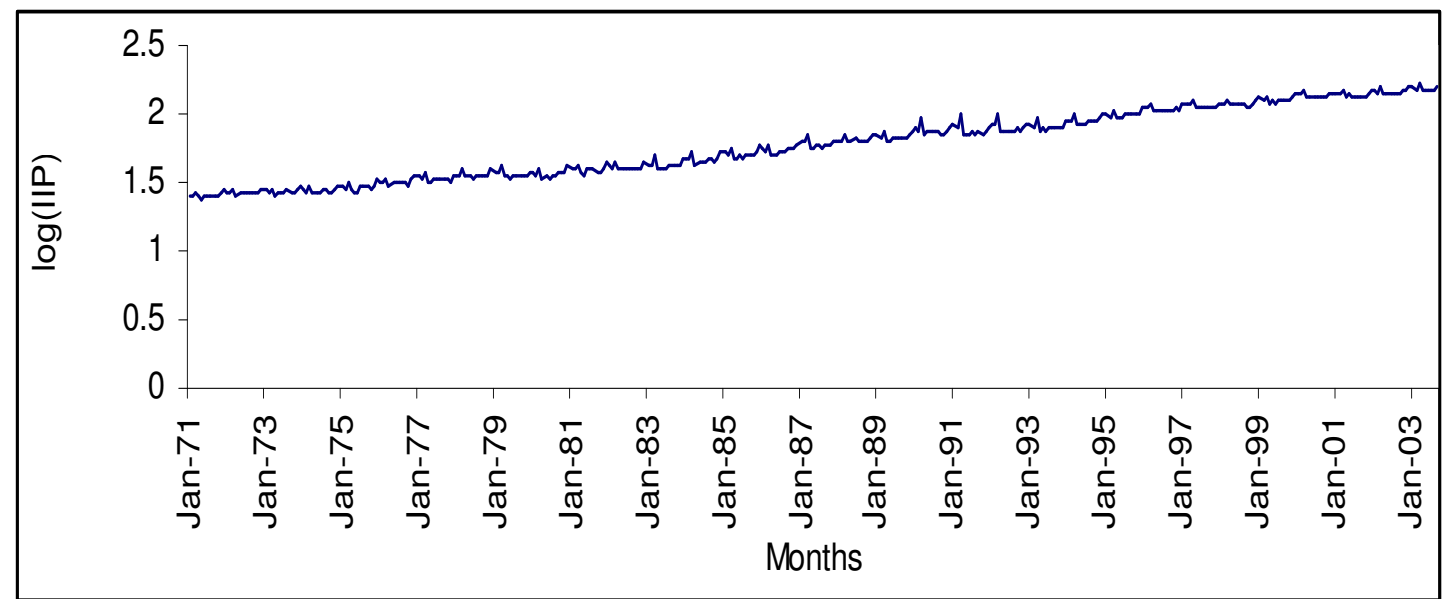

The standard unit root tests - Augmented Dickey Fuller (ADF) and Phillips Perron (PP) - have been performed for all the three series, i.e., $p$ and $y$, both with trend and without trend. The results of unit root tests for all the series have been reported in Table 1 as follows. All the above series are found to be integrated of order one. ${ }^{2}$ This is true irrespective of the presence of a trend variable. Therefore, we take their first differences to make them stationary. The resultant series are now $\Delta p$ and $\Delta y$ which show the growth of the respective series. ${ }^{3}$ We will use $\Delta p$ and $\Delta y$ in our models, since $Z_{t}$ needs to be a covariance stationary vector. ${ }^{4}$

\section{Results}

The results are presented as charts (figures 3 and 5) and tables (2 and 3) of the forecast error decompositions, impulse response functions of $\Delta y, \Delta p$ and $y$ to supply and demand shocks (Figures 2 and 4 ), for first the VSC then the HSC. ${ }^{5}$

The $k$ month-ahead forecast error in output is defined as the difference between the actual value of output and its forecast as of $k$ months earlier. This forecast error is due to both unanticipated demand and supply shocks in the last $k$ months. The

\footnotetext{
${ }^{2}$ We have test for cointegration among $p$ and $y$. However, we did not get a cointegrating relation among them on the basis of trace statistic.

${ }^{3}$ Since all the series are in logarithmic terms.

${ }^{4}$ Since both $\Delta p$ and $\Delta y$ are stationary, Blanchard and Quah's (1989) decomposition procedure can be applied in the presence of our long run restrictions. Also see Quah (1995).

${ }^{5}$ The estimation is done with RATS package using a programme developed by Lack and Lenz (1999).
} 
Table 1: Tests of Unit Roots

\begin{tabular}{|c|c|c|c|c|c|c|c|}
\hline \multirow{4}{*}{ Variables } & \multicolumn{3}{|c|}{ Without Trend } & \multicolumn{3}{c|}{ With Trend } & \multirow{2}{*}{ Remarks } \\
\cline { 2 - 7 } & $P P(5)$ & $D F$ & $A D F(5)$ & $P P(5)$ & $D F$ & $A D F(5)$ & \\
\hline$p$ & -1.759 & -2.386 & -1.677 & -1.969 & -1.244 & -2.028 & $I(1)$ \\
& $(0.401)$ & $(0.146)$ & $(0.443)$ & $(0.619)$ & $(0.900)$ & $(0.587)$ & \\
iip & -0.462 & -1.004 & -0.327 & -10.081 & -10.081 & -5.313 & $I(1)$ \\
& $(0.900)$ & $(0.752)$ & $(0.923)$ & $(0.000)$ & $(0.000)$ & $(0.000)$ & \\
$y$ & -2.358 & -2.537 & -2.798 & -2.479 & -2.479 & -2.436 & $I(1)$ \\
$\Delta p$ & $(0.154)$ & $(0.107)$ & $(0.059)$ & $(0.340)$ & $(0.340)$ & $(0.362)$ & \\
$\Delta y$ & -12.572 & -12.452 & -7.41 & & & & $I(0)$ \\
& $(0.000)$ & $(0.000)$ & $(0.000)$ & & & & \\
& -28.331 & -27.599 & -7.943 & & & & $I(0)$ \\
\hline
\end{tabular}

${ }^{*} p$, iip and $y$ are respectively WPI, IIP and real output in log terms.

${ }^{* *} \Delta p$ and $\Delta y$ are the first difference of $p$ and $y$ respectively.

horizontal axis gives months and the vertical axis gives the effects in percentage. The figure for output at horizon $k,(k=1, \cdots, 48)$ gives the percentage of variance of the $k$ month-ahead forecast error due to demand and supply shocks respectively, which add up to 100. Figure 3 and 5 give the FEVD for inflation, output growth and output levels.

These forecast error variance decompositions (FEVD) have been presented in Table 2 and 3 also. The major impact of a shock is over within 24 months but small variations continue beyond. The standard error bands show satisfactory precision except for longer-run output level response. The graphs illustrate the tables to which we largely confine our interpretations.

\section{$3.1 \quad$ VSC}

Impulse response functions (IRF) of the VSC model are given in Figure 2. Panel (a) and (b) represent IRF of real output growth $(\Delta y)$ due to supply shocks and demand shocks respectively. Supply shocks raise $\Delta y$ in the first month which comes down in next few months. After that it fluctuates and approaches neutralization. More or less, $\Delta y$ follows a similar pattern in response to demand shocks. In sum, both the supply and demand shocks have an immediate positive impact on growth in real output. 
On the other hand, supply shocks have an immediate negative impact on inflation $(\Delta p)$ which rises in few months and fluctuates before getting neutralised. However, demand shocks push $\Delta p$ up in the first month. Then $\Delta p$ falls back and it takes relatively longer time to get neutralised. The IRF of supply and demand shocks on inflation are given in panel (c) and (d) in Figure 3.

Looking at the panel (e) and (f) of Figure 3 (which give the IRF of $y$ due to supply shocks and demand shocks respectively), it is clear that supply shocks have a permanent positive impact on real output, whereas demand shocks are found to have no impact in the medium to long-run.

\section{Figure 2: Impulse Response Functions in VSC Model}

(a) Response of $\Delta y$ due to supply shocks

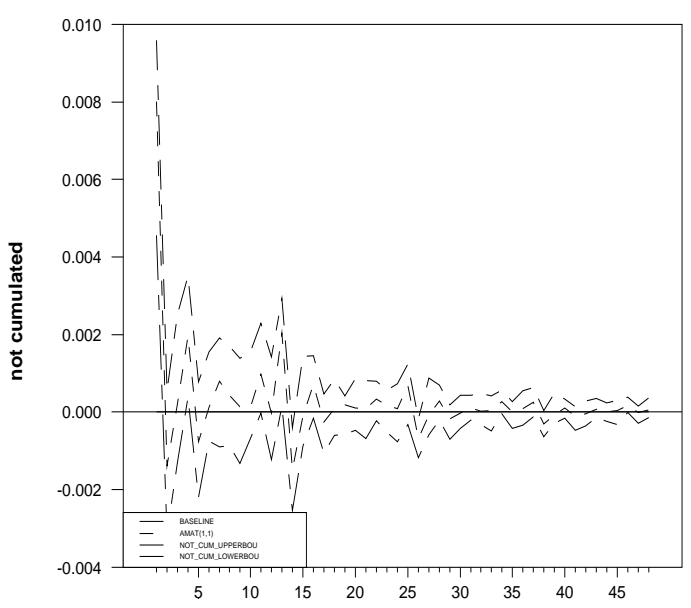

(c) Response of $\Delta p$ due to supply shocks

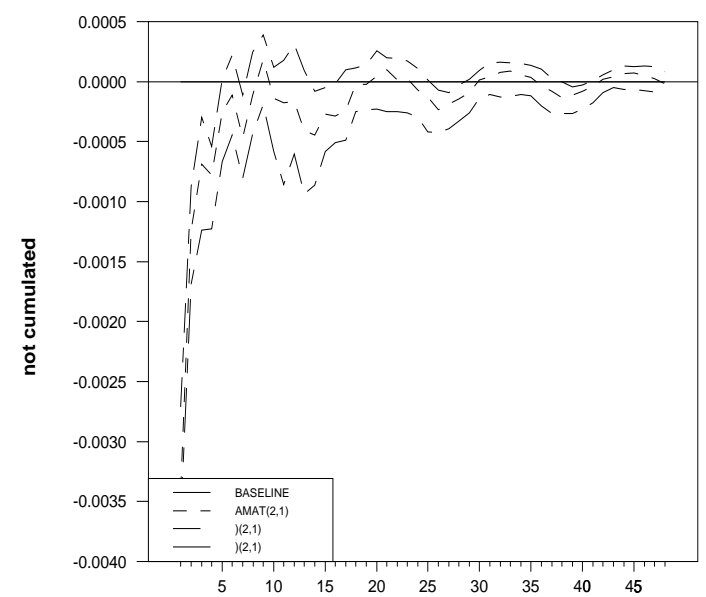

(b) Response of $\Delta y$ due to demand shocks

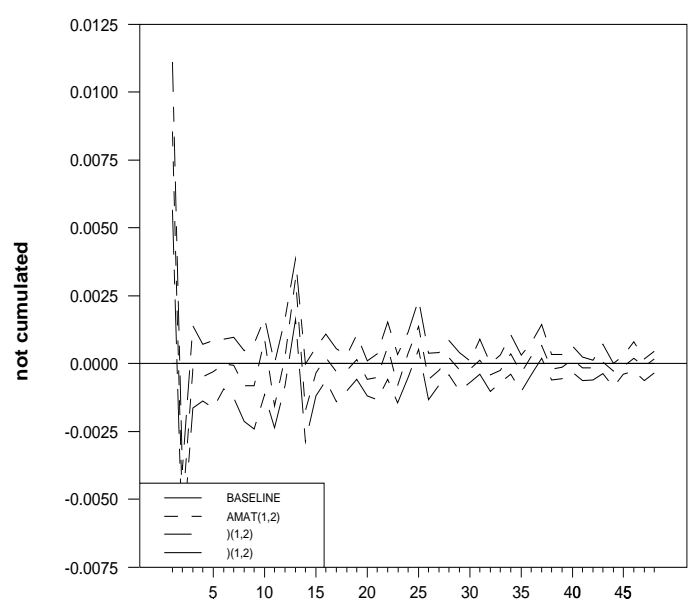

(d) Response of $\Delta p$ due to demand shocks

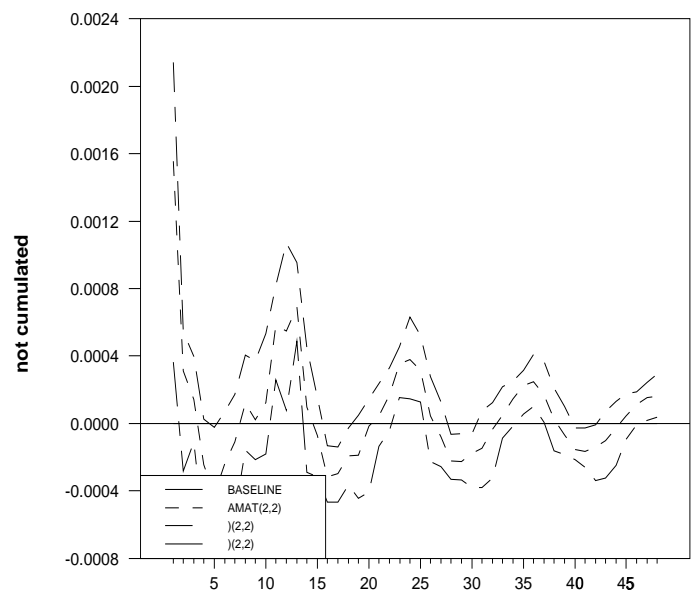


(e) Response of $y$ due to supply shocks

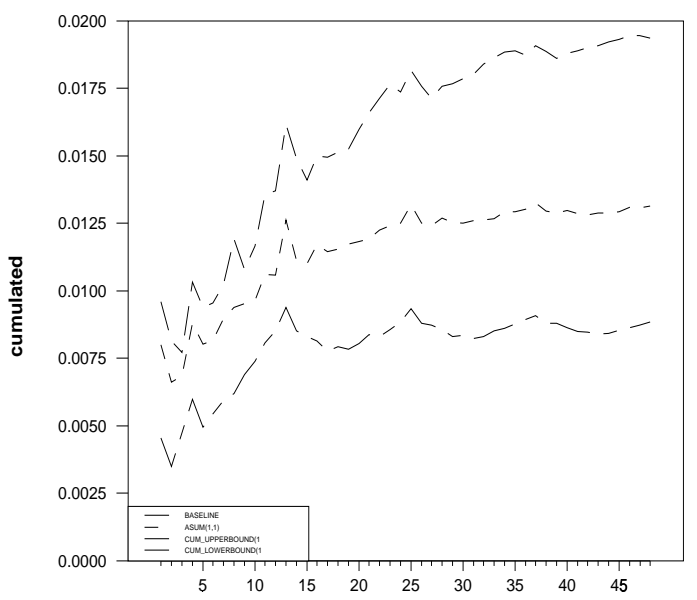

(f) Response of $y$ due to demand shocks

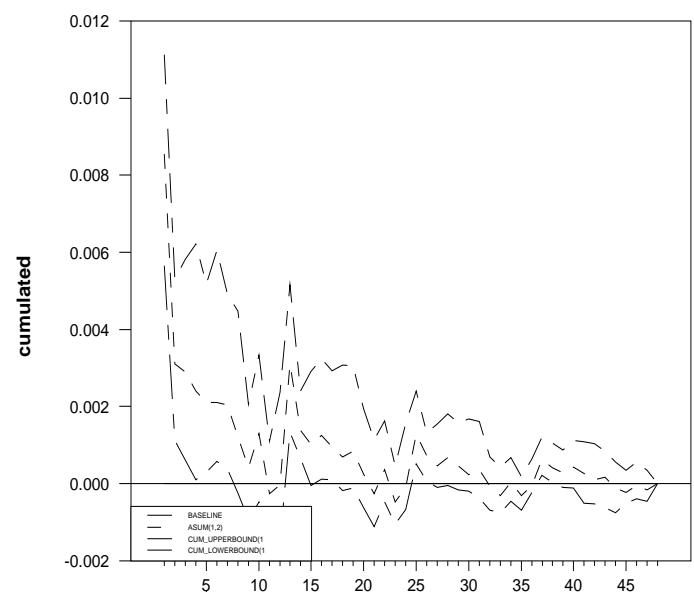

The FEVD of the VSC model have been presented in Figure 3 and Table 2 below. It is clear from the FEVD that although the effect of demand shocks on output does fall after one year, it is quite substantial in the one year (53.26 in the first month compared to 0.1 in Quah and Vahey (1995)). Therefore the identification imposed is not well supported. It is applicable, however, since approximate output neutrality does hold at the mediumrun horizon. But the VSC as an indentification procedure is dubious also since supply shocks have a sustained large impact on inflation (39.02 at 48 months compared to 7.3 for Quah and Vahey (1995)). Demand accounts for only 61 percent of the variance in the 48 month forecast error in inflation. Supply shocks do have a sustained impact on output levels accounting for 47 percent at the one month horizon and going up to 98 percent by 48 months.

Figure 3: FEVD in VSC Model

(a) FEVD of Inflation in VSC Model

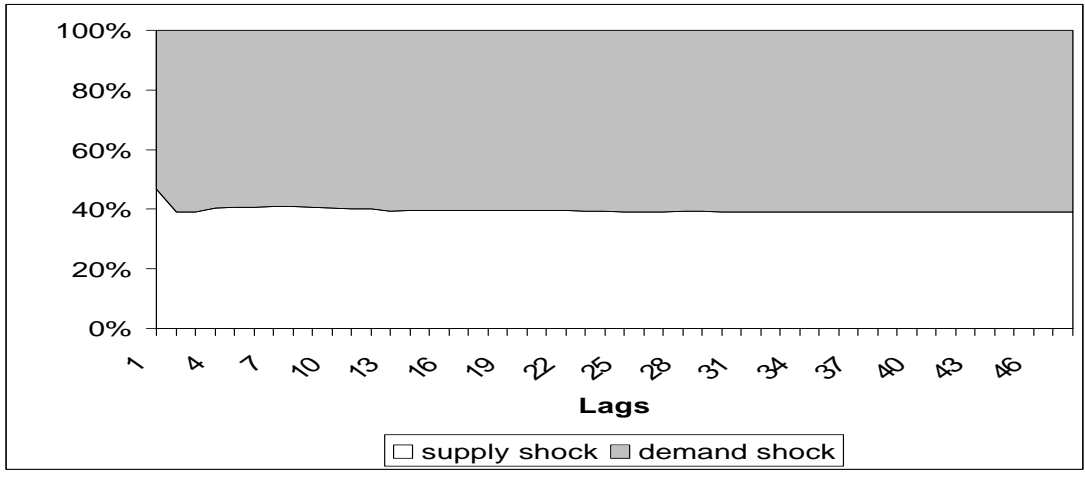


(b) FEVD of Real Output Growth in VSC Model

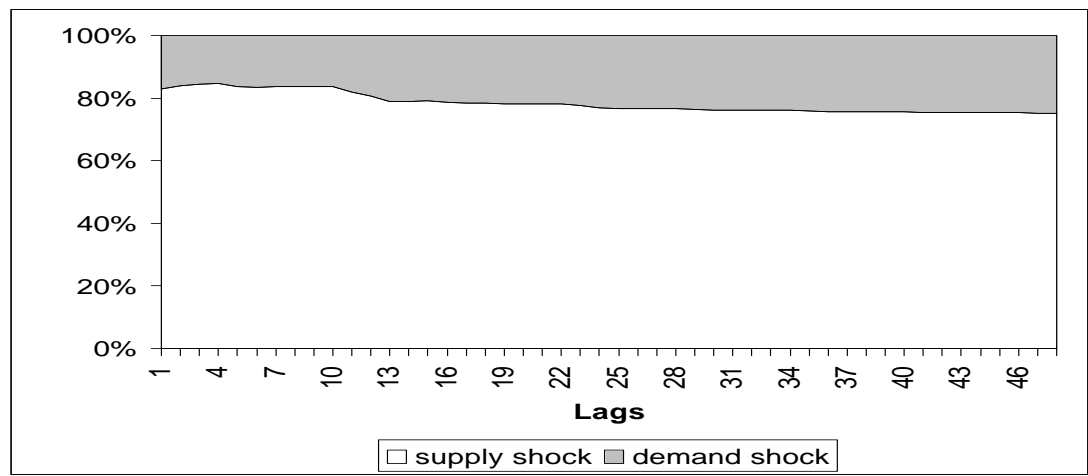

(c) FEVD of Real Output In VSC Model

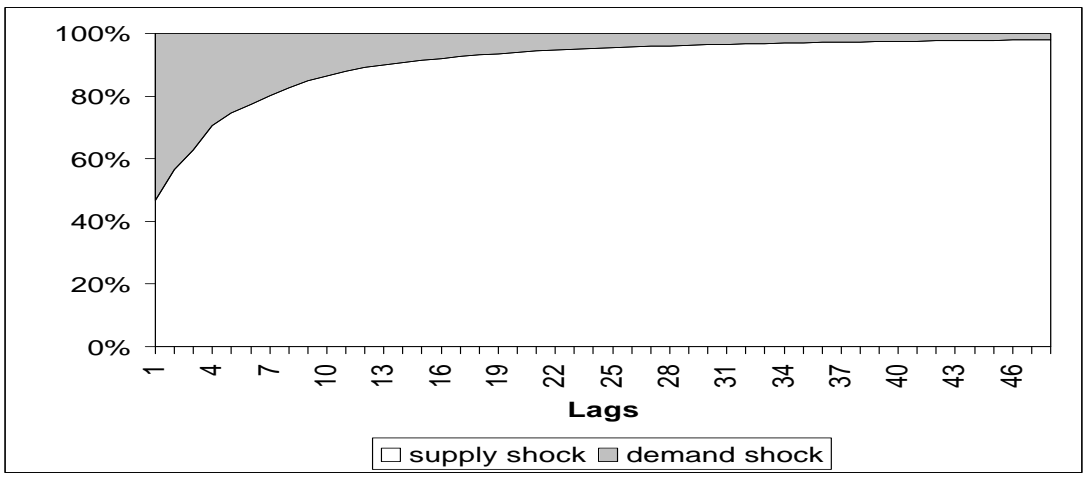

Table 2: FEVD in VSC Model

\begin{tabular}{|c|c|c|c|c|c|c|}
\hline \multirow{2}{*}{ Months } & \multicolumn{2}{|c|}{$\Delta p$} & \multicolumn{2}{c|}{$\Delta y$} & \multicolumn{2}{c|}{$\mathrm{y}$} \\
\cline { 2 - 7 } & supply & demand & supply & demand & supply & demand \\
\hline 1 & 46.74 & 53.26 & 82.80 & 17.20 & 46.74 & 53.26 \\
2 & 39.16 & 60.84 & 83.96 & 16.04 & 56.60 & 43.40 \\
3 & 39.17 & 60.83 & 84.32 & 15.68 & 62.92 & 37.08 \\
4 & 40.46 & 59.54 & 84.58 & 15.42 & 70.55 & 29.45 \\
12 & 40.20 & 59.80 & 80.69 & 19.31 & 89.25 & 10.75 \\
24 & 39.34 & 60.66 & 77.00 & 23.00 & 95.29 & 4.71 \\
36 & 39.10 & 60.90 & 75.68 & 24.32 & 97.16 & 2.84 \\
48 & 39.02 & 60.98 & 75.09 & 24.91 & 98.00 & 2.00 \\
\hline
\end{tabular}




\subsection{HSC}

Figure 4 presents the IRF of the HSC model. From panel (a) and (b) of Figure 4, it is clear that both supply and demand shocks raise inflation in the first month which falls back in the next. However, it seems that the impact of demand shocks takes a longer time to be neutralised as compared to that of supply shocks. Panel (c) and (d) presents the IRF of $\Delta y$ with respect to supply shocks and demand shocks respectively. It can be seen that growth in output falls in the first month due to supply shocks, and recovers gradually. After four to five months, it starts fluctuating and then it gets neutralised. However, demand shocks raise $\Delta y$ in the first month and get neutralised through fluctuations.

\section{Figure 4: Impulse Response Functions in HSC Model}

(a) Response of $\Delta p$ due to supply shocks

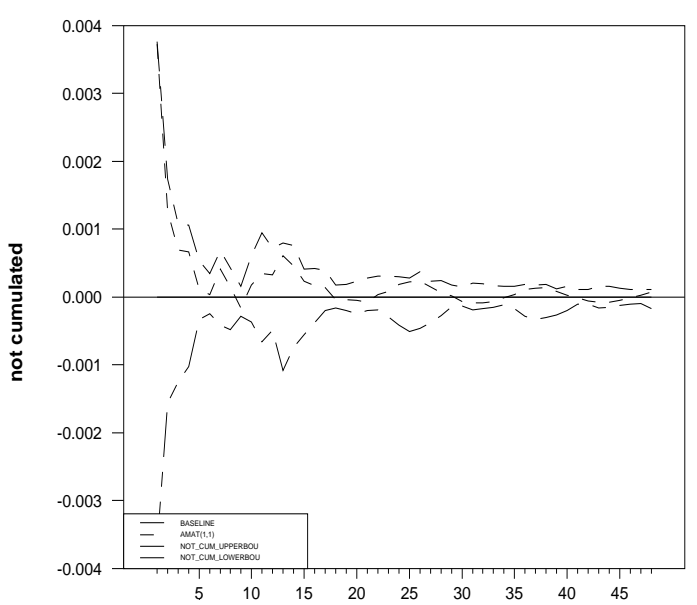

(c) Response of $\Delta y$ due to supply shocks

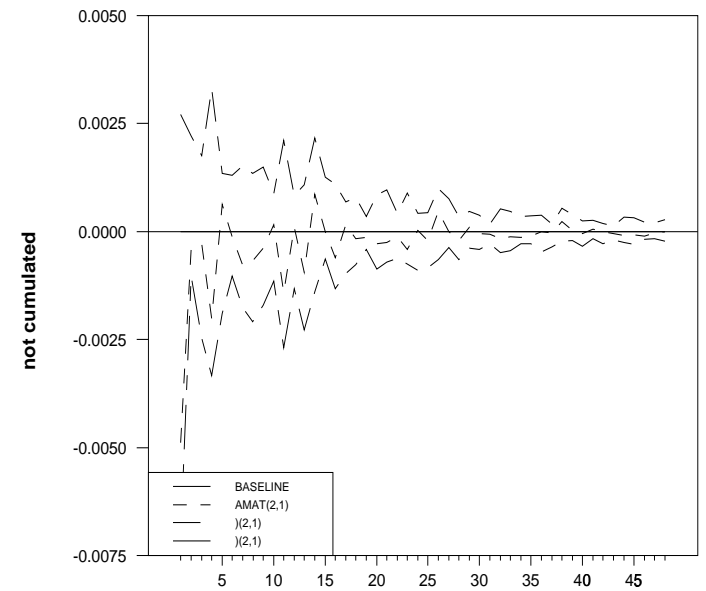

(b) Response of $\Delta p$ due to demand shocks

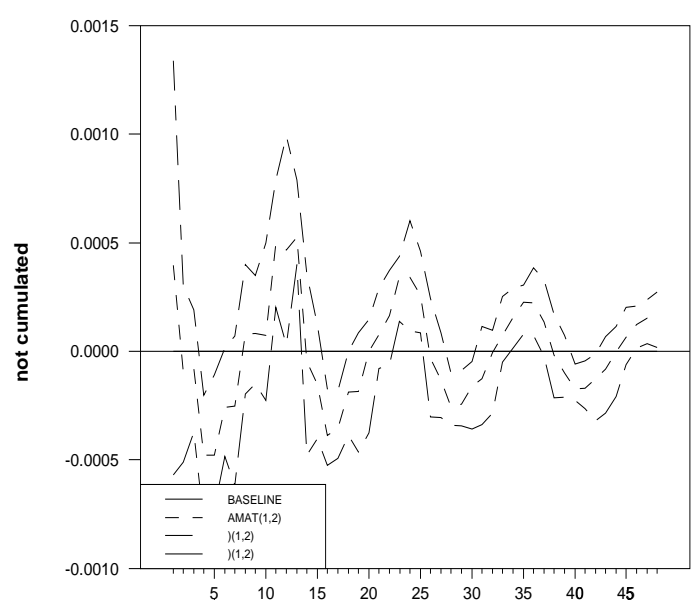

(d) Response of $\Delta y$ due to demand shocks

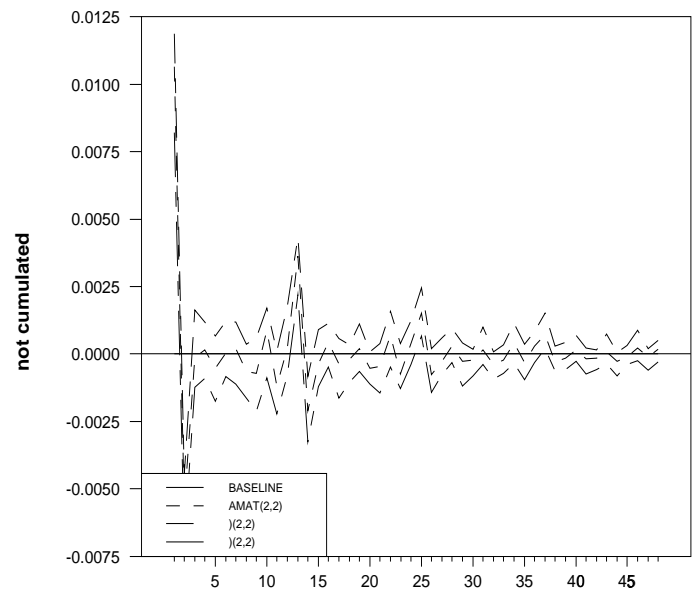


(e) Response of $y$ due to supply shocks

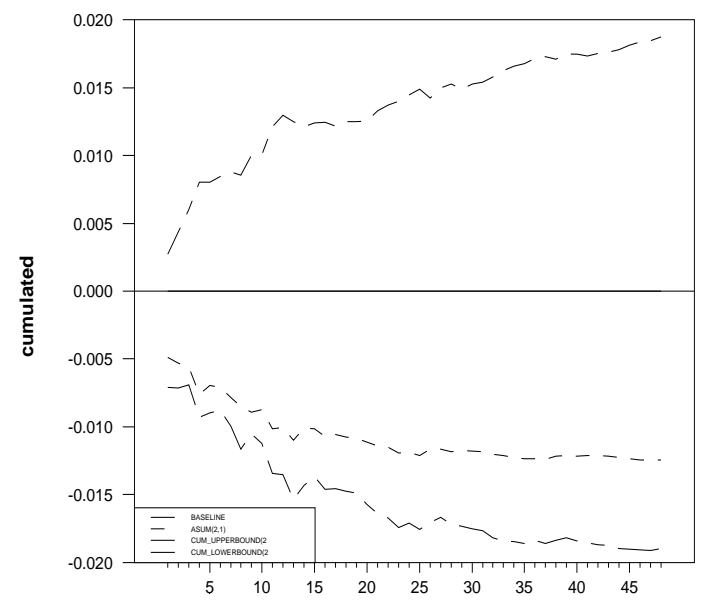

(f) Response of $y$ due to demand shocks

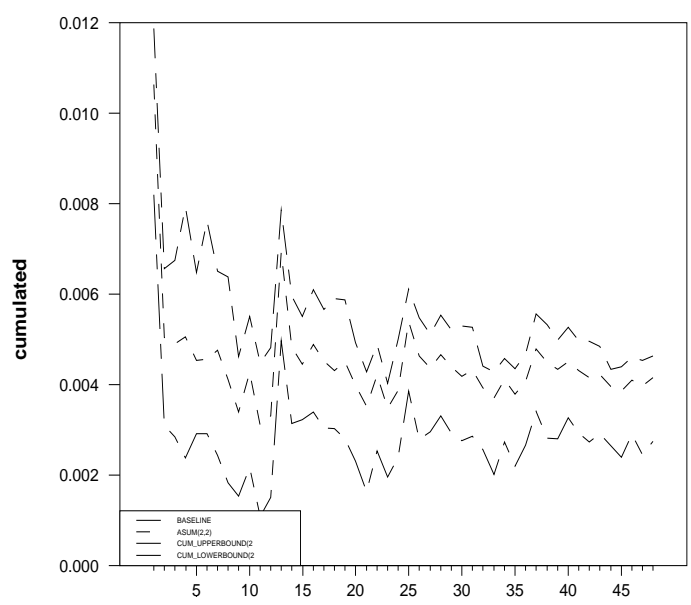

Real output declines continuously due to supply shocks, although the estimation is not precise. Demand shocks raise $y$ in the first month and then $y$ moves slowly towards a stable positive value.

In the case of the HSC the adjustment of inflation to demand shocks is fast with an effect of only about 1 percent upto three months, but after that it rises gradually to about 13 percent by the 48th month. This supports the identification imposed suggesting that the supply curve is highly elastic at all horizons.

Figure 5: FEVD in HSC Model

(a) FEVD of Inflation in HSC Model

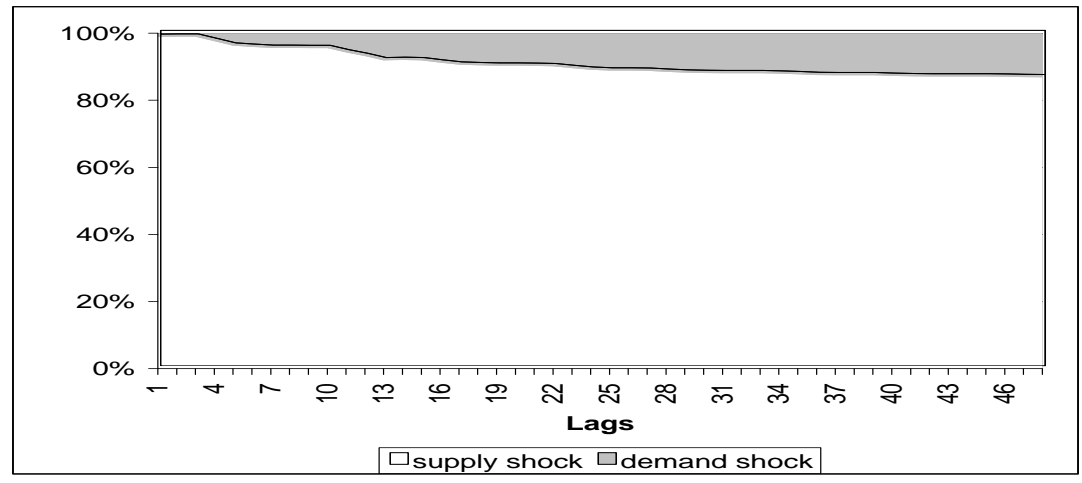


(b) FEVD of Real Output Growth in HSC Model

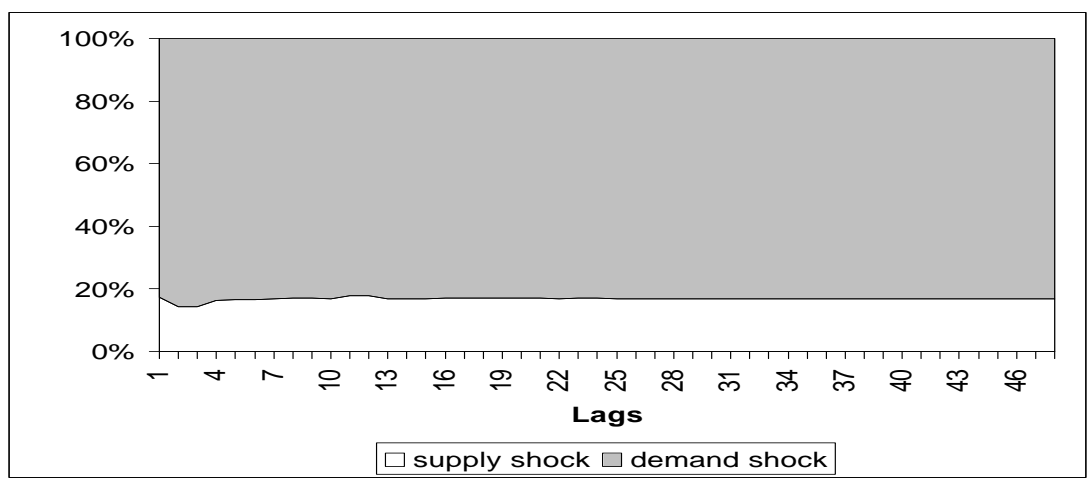

(c) FEVD of Real Output In HSC Model

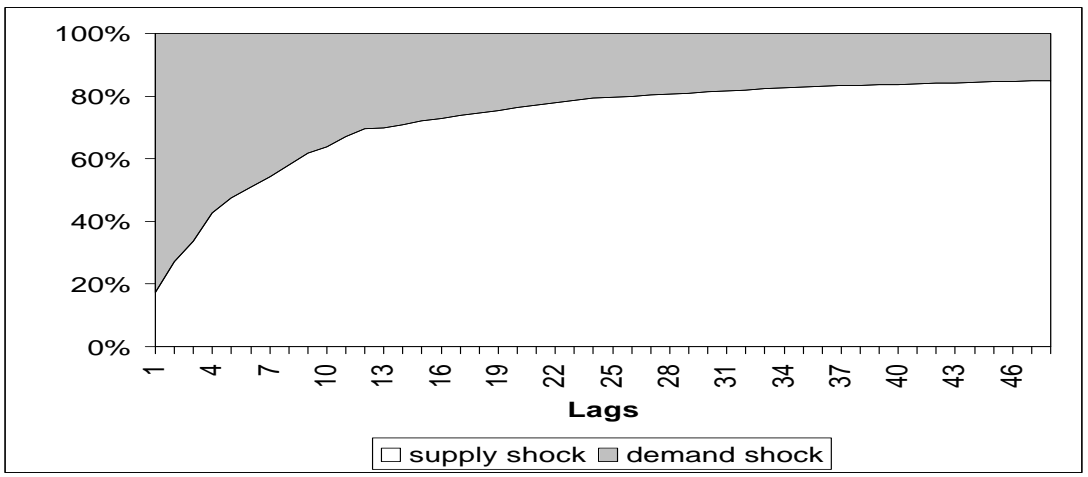

Table 3: FEVD in HSC Model

\begin{tabular}{|c|c|c|c|c|c|c|}
\hline \multirow{2}{*}{ Months } & \multicolumn{2}{|c|}{$\Delta p$} & \multicolumn{2}{c|}{$\Delta y$} & \multicolumn{2}{c|}{$\mathrm{y}$} \\
\cline { 2 - 7 } & supply & demand & supply & demand & supply & demand \\
\hline 1 & 98.88 & 1.12 & 17.45 & 82.55 & 17.45 & 82.55 \\
2 & 98.94 & 1.06 & 14.29 & 85.71 & 27.25 & 72.75 \\
3 & 98.94 & 1.06 & 14.33 & 85.67 & 33.77 & 66.23 \\
4 & 97.62 & 2.38 & 16.34 & 83.66 & 42.73 & 57.27 \\
12 & 93.15 & 6.85 & 17.73 & 82.27 & 69.63 & 30.37 \\
24 & 89.11 & 10.89 & 16.97 & 83.03 & 79.43 & 20.57 \\
36 & 87.53 & 12.47 & 16.82 & 83.18 & 83.18 & 16.82 \\
48 & 86.82 & 13.18 & 16.78 & 83.22 & 85.02 & 14.98 \\
\hline
\end{tabular}

Thus demand shocks have little sustained impact on inflation. Supply shocks account for the major part of measured inflation with supply shocks accounting for almost the entire FEVD at short horizons and staying at 87 percent at 48 months. Demand shocks do have a 
sustained impact on output levels with an initial impact of 82.55 coming down but staying substantial at 15 percent by 48 months. Thus demand shocks have persistent effects on output. Moreover, they have a very large effect on output growth.

One major switch in the two identifications is the reversal of the impact of supply and demand shocks on output growth. The size of the two is almost exactly reversed with demand shocks accounting for 82-86 percent of output growth under the HSC [Figure 5 (b)], and supply shocks accounting for 75-85 [Figure 5 (a)] percent of growth under the VSC. At long horizons supply shocks account for the major part of output levels in both, as must be the case, but demand has a sustained and substantial effect under the HSC. The impulse response for supply shocks is not precisely estimated but it suggests that the cumulated impact of supply shocks alone would be negative without supporting demand which stabilize long term $y$ at a positive level.

While reality probably lies somewhere in the middle of our two extreme identifying assumptions, the results suggest that on the whole the long-run supply curve is highly elastic for the Indian economy, so that the HSC needs to be kept in mind in designing macroeconomic policy for the economy. It has the implication that macroeconomic policies that maintain demand are a pre-requisite for growth to be high.

\section{Historical size and effects of demand and supply shocks}

The Figures (6 and 7) show the contribution of structural demand and supply shocks to annual inflation and IIP output growth across the two identification schemes ${ }^{6}$. The effect of demand on output shown in Figure 6 (a) is calculated as a residual, substracting the structural supply shock from $\Delta y$. Similarly, the effect of demand on inflation under the HSC is a residual [Figure 7 (b)].

Although their relative size varies the structure of demand and supply shocks is similar across the two identifications, implying that the distinction betwen demand and supply shocks and their estimation is robust. Turning points are well captured and the estimated shocks match historic events such as oil price hikes and industrial recessions well.

Supply shocks dominate, but demand seems to have played a pro-cyclical role thus decreasing growth and increasing inflation under negative supply shocks. The oil shocks show up as very sharp supply shocks in the seventies. While demand fluctuated and fell after these supply shocks it recovered somewhat in the eighties in the residual VSC decomposition. The macro stabilization adopted in the early nineties shows up as a sharp negative demand and supply shocks. The 1997 recession in industrial output, following the high growth period, is clearly due to a sharp negative demand shock while supply remained positive. This is the period when real interest rates were raised drastically in response to rupee fluctuations.

\footnotetext{
${ }^{6}$ The shocks are derived using monthly variables and then aggregated by addition. Since the variables are in logarithms this gives an approximation to the annual series. The monthly results are available on request.
} 
During the nineties structural adjustment seems to have resulted in largely positive supply shocks but demand was low and prevented higher growth from setting in. Policy could not translate the increased potential into actual output growth. In the HSC FEVD we saw that demand shocks dominate output growth. The demand shocks in the eighties and nineties [Figure 7 (a)] are as large as the supply shocks and may partly explain the failure to achieve high growth.

Inflation was also dominated by supply shocks, with structural demand shocks small in magnitude compared to supply shocks in the VSC, and demand slowdowns (with demand measured as residuals), following supply shocks, aggravating inflation in the HSC. This is particularly clear in the decade of the nineties where structural demand shocks peaked in the mid-nineties in the VSC [Figure 6 (b)] but both demand and supply fell thereafter, pulling inflation down. But the HSC shows that the residual demand category kept inflation from fully benefiting from supply improvements. The inflation series lies between the largely negative supply shocks and positive demand. But since demand shocks on output were negative in this period low output demand seems to have translated into higher inflation implying some countercyclical mark-ups or cost factors. The seventies had the highest rates of inflation, due to the oil price induced steep fluctuations in both demand and supply. Even in the VSC, where because of the long-run vertical supply curve imposed demand shocks should dominate inflation, we saw in the FEVD that supply retains a share of 40 percent (Table 2).

The monthly series show that across the decompositions the supply components are mildly positive in periods of rapid growth as compared to large positive and negative fluctuations in periods of low growth.

Sharp fluctuations in demand accompany periods of growth slowdown, and inflation can be high even under negative demand shocks.

The results demonstrate downward inflexibility of the price level. Inflation is pulled sharply up by positive supply shocks and brought down by negative, but monthly inflation rarely falls below zero, and on the rare occasions it does become negative it is by miniscule amounts.

\section{Conclusion}

In a two equation Structural Vector Autoregression (SVAR) identifications of a vertical and then a horizontal supply curve are successively imposed on Indian time series inflation and industrial output growth data. Because supply shocks have large impact on inflation and demand has a large effect on output growth and a persistent effect on output levels, on balance the evidence favours a high elasticity of long-run supply.

The structural demand and supply shocks estimated capture historical recessions and turning points well. Policy affects both supply and demand shocks but macroeconomic policy affects demand. The demand shocks seem to have aggravated negative supply shocks or failed to take full advantage of positive supply side developments. 
In the more open economy of the nineties interest and exchange rate policy had a rising impact. An extended SVAR which brings in these variables may be able to further refine our understanding of macroeconomic policy impact. Our analysis is also restricted by the use of the IIP series as a proxy for output. Monthly output series are not yet available in India.

\section{Figure 6}

(a) Real Output Growth and its Components in VSC model

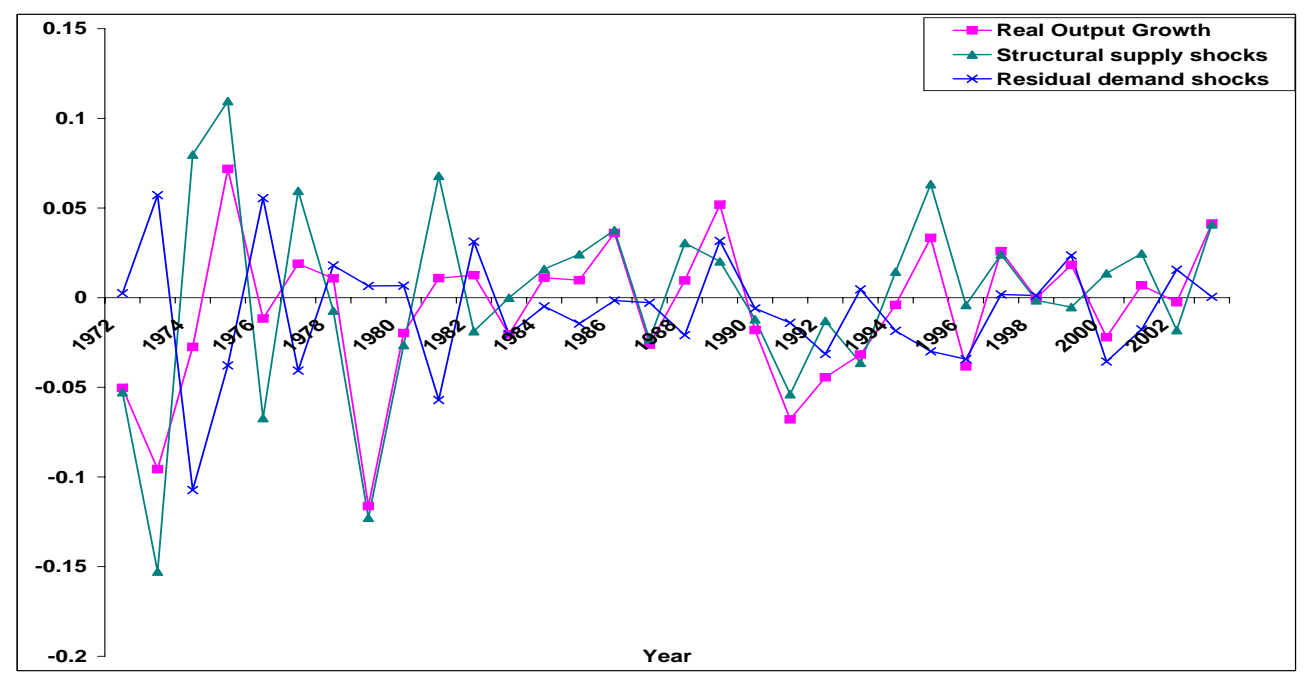

(b) Inflation and its Components in VSC model

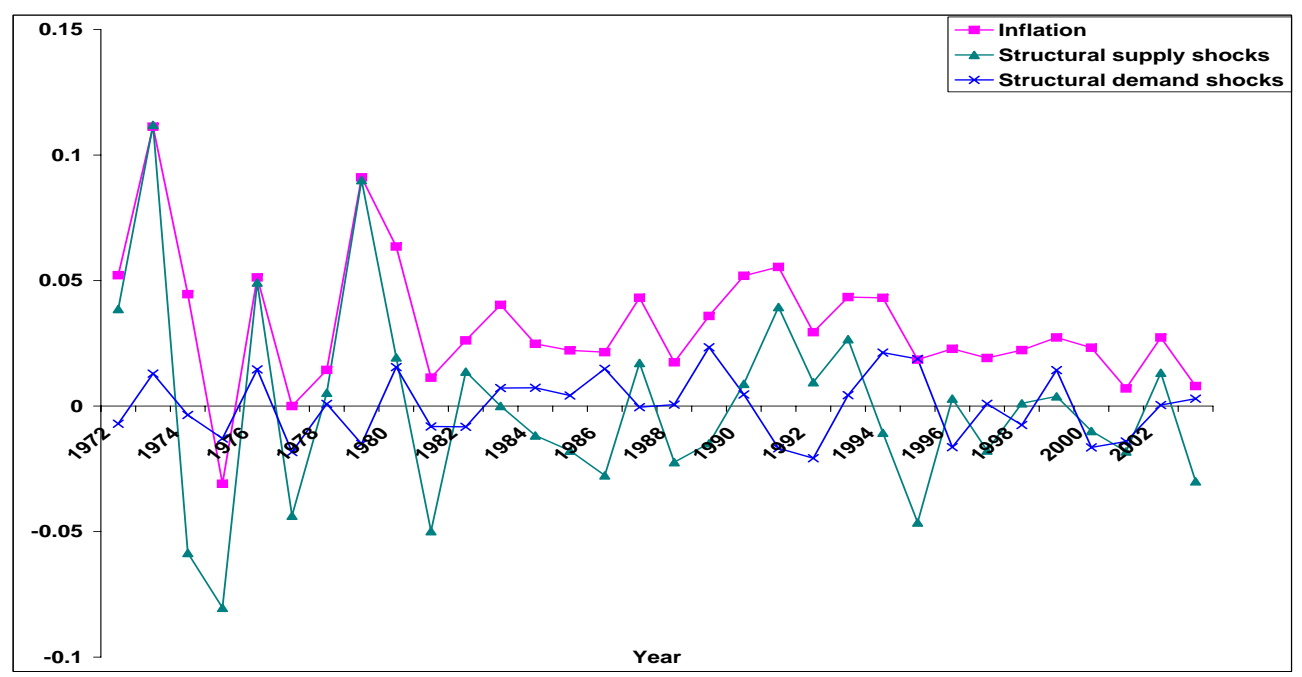




\section{Figure 7}

(a) Real Output Growth and its Components in HSC Model

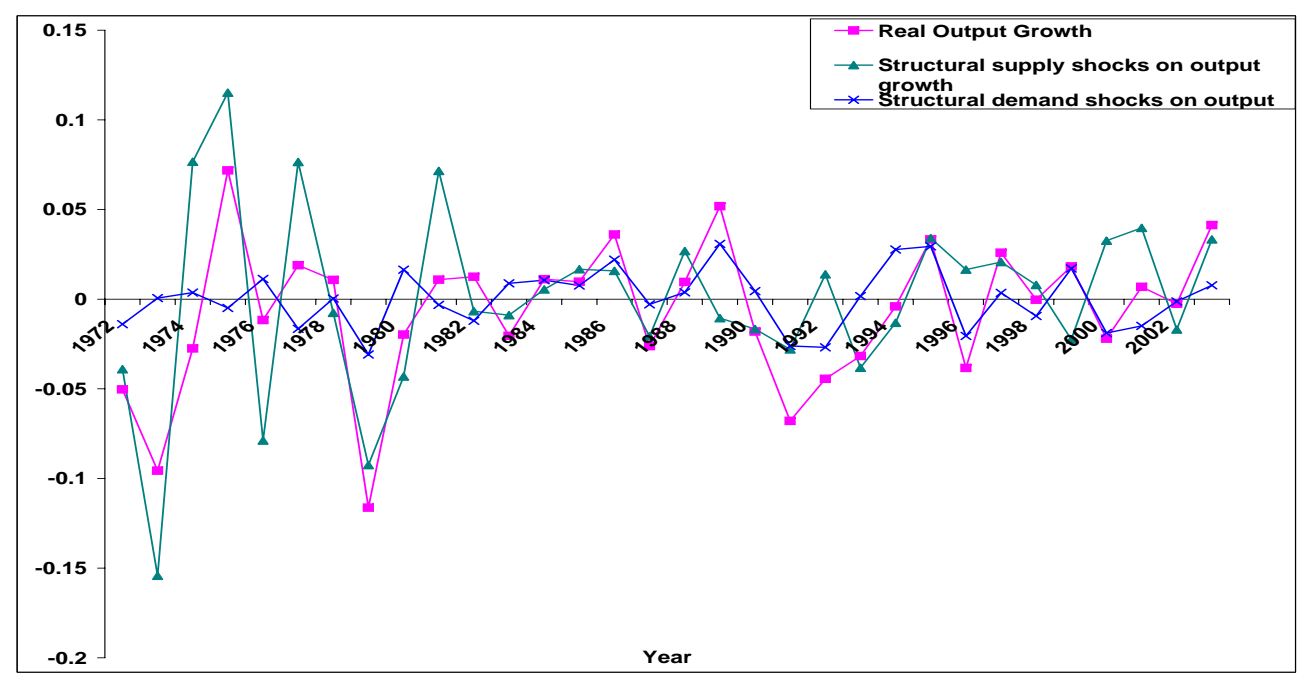

(b) Inflation and its Components in HSC Model

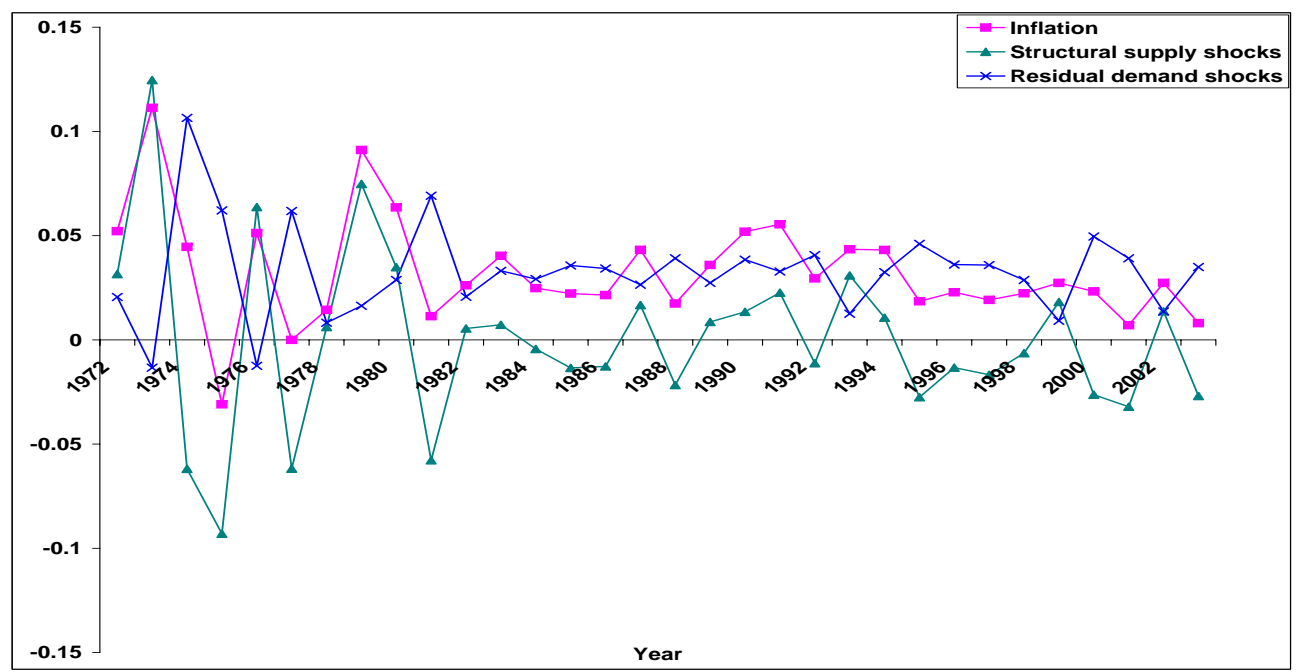




\section{References}

1. Bjornland H. C. (2001), "Identifying Domestic and Imported Core Inflation", Applied Economics, Vol. 33, pp. 1819-1831.

2. Blanchard O. J. and D. Quah (1989), "Dynamic Effects of Aggregate Demand and Supply Disturbances", American Economic Review, Vol. 79 (4), pp. 655-671.

3. Blanchard O. J. and L.H. Summers (1987), "Hysterisis in Unemployment", European Economic Review, Vol. 31, pp. 288-295.

4. Enders, Walter (2004), "Applied Econometric Time Series", John Wiley and Sons, Second Edition.

5. Farmer, R. (1999), "The Macroeconomics of Self-Fulfilling Prophecies", Cambridge, MA: MIT Press, Second Edition.

6. Giannini C. (1992), "Topics in Structural VAR Econometrics", Lecture Notes in Economics and Mathematical Systems, Springer Verlag.

7. Lack, Caesar and Carlos, Lenz (1999), A Program for the Identification of Structural VAR Models, http://www.unibas.characteristic/wwz/makro/svar

8. Mankiw, G. and D. Romer (eds.) (1991), "New Keynesian Economics: Coordination Failures and Real Rigidities", Cambridge, MA: NBER/MIT Press.

9. Quah D. (1995) "Misinterpreting Dynamic Effects of Aggregate Demand and Supply Disturbances", Economic Letters, Vol. 49, pp. 247-250.

10. Quah, Danny and Shaun P. Vahey (1995), "Measuring Core Inflation", Economic Journal Vol. 105 (432), PP. 1031-1044. 